\title{
Investigation of the Causes of Malfunctions of Special Electrical Equipment of Pumping Stations
}

\author{
${ }^{1}$ AyubjonVokhidov, ${ }^{2}$ Ekaterina Churakova \\ ${ }^{1}$ Assistant of Department of Power Supply and Automation, Polytechnic institute of Tajik Technical University, \\ Khujand, Republic of Tajikistan \\ ${ }^{2}$ Assistant of the Department of Engineering Graphics,Moscow Aviation Institute \\ (National Research University), Russia, Moscow
}

Article History: Received: 11 January 2021; Accepted: 27 February 2021; Published online: 5 April 2021

\begin{abstract}
The task of this work was to consider the main technical parameters of pumping stations that affect the operating modes and the overall reliability of a special power supply system. Also, the technological processes of the irrigation pumping station were investigated and the analysis of mechanical and parametric characteristics, the causes of the asynchronous operation of mechanisms and the failure of the pumping units themselves was carried out. As a result of the work, a method for calculating the voltage drop was proposed, a new independent algorithm for calculating the static stability and the stability margin for the active power of special electrical equipment was developed.
\end{abstract}

Keywords: pumping station, productivity, technical and mechanical parameters, energy-intensive consumers, synchronism, direct criteria of static stability.

\section{Introduction}

The Khoja Bakyrgan-1 (KB-1) pumping station, which serves for irrigation of thousands of hectares of land, is located in the north of the BabajanGafurov region of the Republic of Tajikistan. It is one of the most important objects of water management, which is powered by the Kairakkum hydroelectric power station of the Sughd energy system of the Republic of Tajikistan [1].

Delivery of bulky goods to hard-to-reach places is very difficult [2] and requires compliance with a number of factors to the engineering infrastructure to accomplish the task [3]. In this case, the delivery and replacement of bulky components describes one of many restrictions. [4].

Transportation options by means of light aircraft also cannot be applied, due to the difficulties with landing

After the operation of the Kairakkum HPP of the Sughd energy system, the Khoja Bakyrgan-1 pumping station was operated. According to the project, the pumping station is supposed to irrigate 9.4 thousand hectares of land planted with cotton and grain. The main consumers of electricity at the KB-1 station are high-voltage synchronous motors [2].

The pumping station has two lifts for pumping water, which pumps water from the Kairakkum reservoir over a distance of more than 1028 meters on the second lift. The first lift of the pumping station was designed to pump and supply water from the reservoir to the second lift. In the first lift of the pumping station, three Pantons are installed with eight synchronous motors of the SDNZ 3-17-56-4U3 type. The installed capacity of the first lift of the pumping station is $48 \mathrm{MW}$, and that of the second lift is $27.2 \mathrm{MW}$, therefore the facility is one of the energy-intensive consumers of the Kairakkum power plant and is included in the first category of electricity consumers [2]. Figure 1 showstheappearanceofthe HB-1 pumpingstation. 


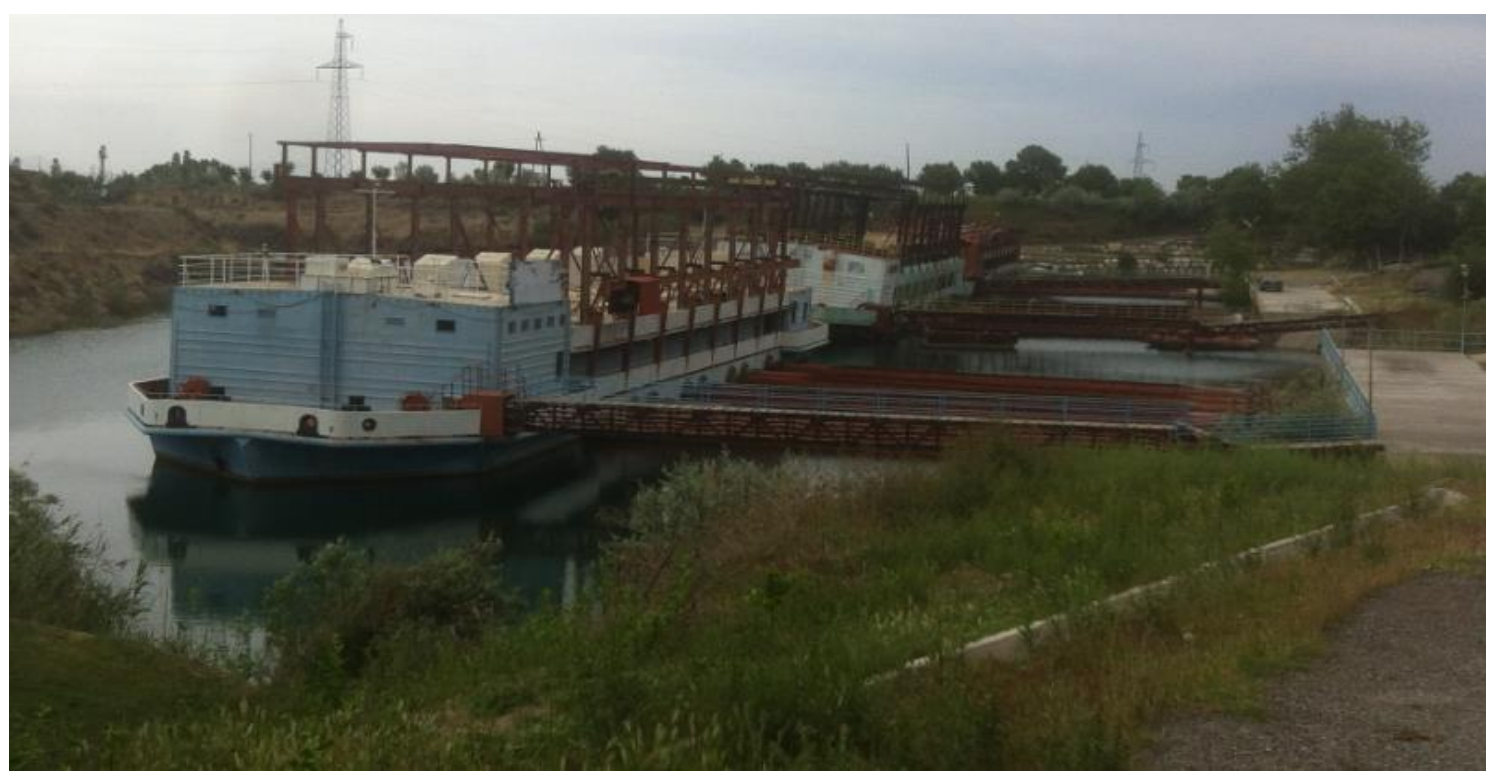

Figure 1. Khoja Bakyrgan - 1 pumping station

\section{Methodology}

According to clause 1.2.13 of the Rules for the Installation of Electrical Installations and the Rules of Technical Operation, the power supply of such large consumers for the reliability and stable operation of large pumping stations belongs to a special group, that is, the 1st category, which allows additional power from a third source, usually not included into the power system [5]. According to the project, the capacity of the pumping station of the first lift of the general block is 4.1472 million $\mathrm{m} 3$ of water per day, and the capacity of the second lift is 2.4192 million $\mathrm{m} 3$. The pumping station is used for irrigation of rural lands in cities and districts of the Sughd region and the northern part of the agro-industrial complexes of the Batken region, which mechanical parameters are given in Table 1 .

Table 1.Mechanical Parameters of Vertical Pump Type 24 NDC

\begin{tabular}{|c|c|c|c|c|c|c|c|}
\hline No & Installation & $\begin{array}{c}\text { Assignm } \\
\text { ent }\end{array}$ & Head, $\mathbf{m}$ & $\begin{array}{c}\text { Perform } \\
\text { ance, } \mathbf{m}^{\mathbf{3}} / \\
\text { hour }\end{array}$ & $\begin{array}{c}\text { Pipediameter, } \\
\mathbf{m m}\end{array}$ & $\begin{array}{c}\text { Diameter } \\
\text { from the } \\
\text { engine, } \mathbf{m m}\end{array}$ & $\begin{array}{c}\text { Length, } \\
\mathbf{m}\end{array}$ \\
\hline 1 & $24 \mathrm{NDC}$ & $\begin{array}{c}\text { Overflo } \\
\text { wingwat } \\
\text { er }\end{array}$ & 70.2 & 7200 & $1730 / 10$ & $800 / 10$ & 1028 \\
\hline
\end{tabular}

The power supply diagram of the pumping stations and the equivalent circuit are shown in Figure 2. 


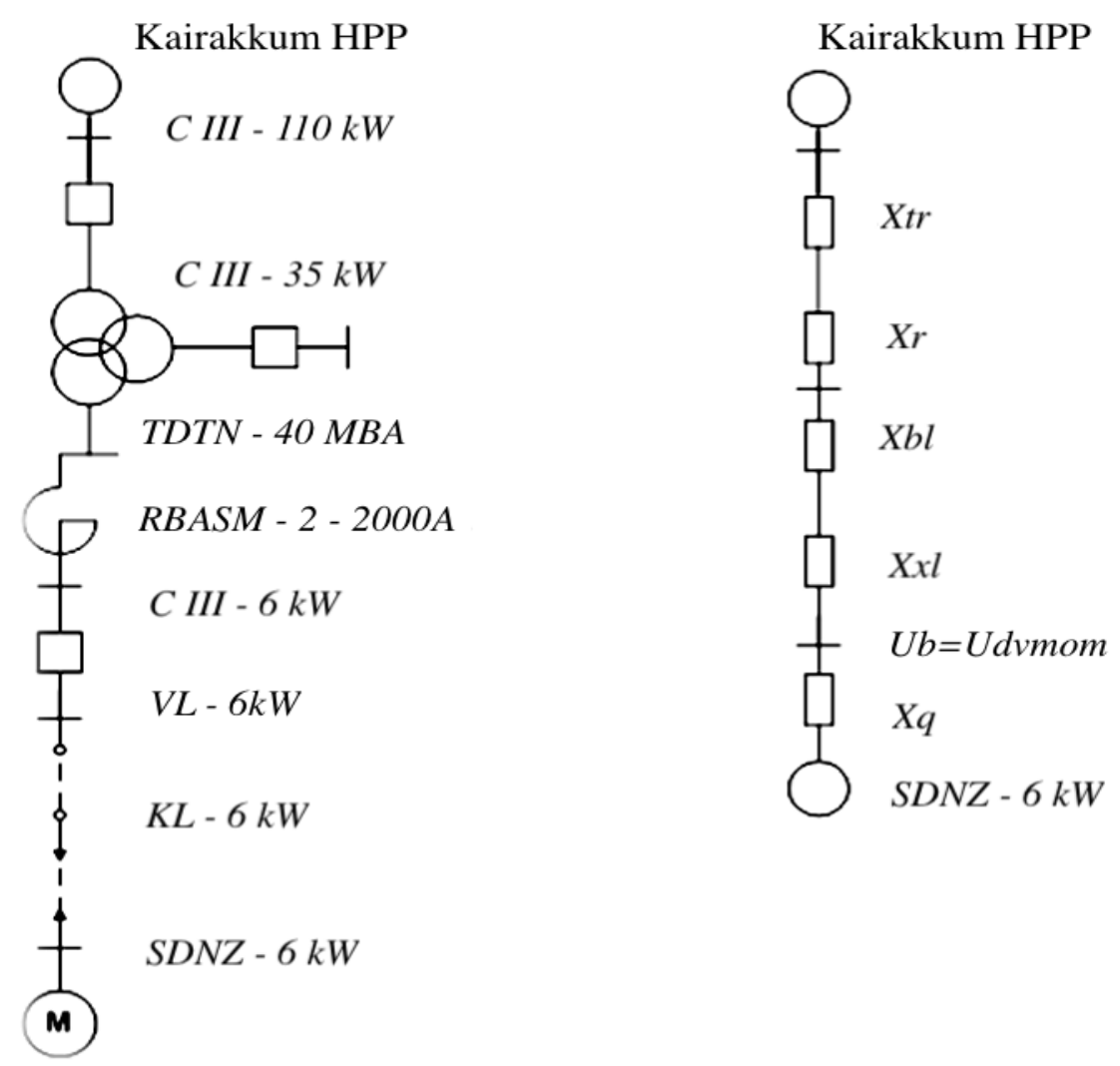

Figure 2. Single-line and equivalent circuit of the Khoja Bakyrgan-1 pumping station

In recent years, there have been frequent problems with synchronicity and failures of high-voltage synchronous motors in the pumping station. The reason for falling out of synchronism of synchronous motors can be voltage fluctuations and deviations, starts of energy-intensive consumers (parallel connection of powerful synchronous motors in pumping stations of Asht (ANS - 1) and Zafarabad region (KNS-2) and other large industrial consumers, frequency ripple in power lines - $500 \mathrm{~kW}$ South-North, triggering of the automatic input of the reserve of the open switchgear circuit breaker - $500 \mathrm{~kW}$ of the Nurek HPP, etc. In addition, triggering of the optoelectronic countermeasures of the switches of the Kairakkum power system and the pumping station's supply network, which changes the transmitted power along this line from $-15 \%$, which affects the technological processes of all irrigation facilities. The characteristics of the engines of several pumping stations are shown in Table 2.

Table 2.Shutdown of pumping station motors in emergency situations of the Sughd power system

\begin{tabular}{|c|c|c|c|c|c|c|c|}
\hline $\begin{array}{c}\text { Switching off the } \\
\text { motors of pumping } \\
\text { stations in emergency } \\
\text { situations of the power } \\
\text { system }\end{array}$ & $\begin{array}{c}\text { Totalpower, } \\
\text { kW }\end{array}$ & \multicolumn{6}{|c|}{ The number of failed electrical equipment } \\
\hline \multicolumn{2}{|c|}{ Disconnection date of $500 \mathrm{~kW}$ lines } & $\begin{array}{c}21.07 .1 \\
6\end{array}$ & $\begin{array}{c}23.07 .1 \\
6\end{array}$ & 24.07.16 & 25.07.16 & \multicolumn{2}{|c|}{ 26.07.16 } \\
\hline H. Bakyrgan1 & 48000 & 12000 & 10000 & 18000 & 8000 & 16000 & 12000 \\
\hline H. Bakyrgan 2 & 27600 & 8000 & 8000 & 16000 & - & 14000 & 4000 \\
\hline Sumchak-1 & 4500 & 4000 & - & 2000 & - & - & - \\
\hline Oktosh -1 & 4230 & 1600 & - & - & 4000 & 2000 & 2000 \\
\hline Samgar1 & 16000 & - & 2000 & 8000 & - & 2000 & 4000 \\
\hline Total & 100330 & 25600 & 20000 & 44000 & 12000 & 4000 & 22000 \\
\hline
\end{tabular}

The main aspects of the unreliable operation of the synchronous motor of the KB-1 pumping station are large voltage deviations in the load node and distribution network, mechanical overloads in the pumping unit, the 
influence of large disturbances in the power system, short interruptions in the power supply of the station and substation. In addition, starting voltage deviations are a negative factor that affects neighboring consumers connected to this bus system of the pumping station. In such emergency situations, the transmission of power to the system is temporarily changed or interrupted, which is a very serious factor for the premature failure of the entire system.

With such aggressive operation, all mechanisms require frequent maintenance or even repair. Rubber products, seals and other elements require special care to protect against moisture and dust [6] [7]. In such cases, one of the best solutions may be the use of unified standard structural elements [8], with greater wear resistance. This introduction will reduce costs, but an increased margin of operation of elements may, on the contrary, lead to an increase in the cost of the work performed.

\section{Discussion}

Based on the foregoing, in order to determine the stability of the operation and productivity of the pumping station, we draw up an algorithm for calculating the effect of voltage reduction on productivity. The electric motor load of the first and second lift of the pumping station are synchronous motors of the SDNZ-17-56-4U3 type with a rated power of $2 \mathrm{MW}$ and $1.6 \mathrm{MW}$, etc. [9].

In the absence of slip, the entire power of the stator electromagnetic field is converted into mechanical power on the shaft of the synchronous motor.

Figure 3 shows the dynamics of the effects of voltage reduction in the distribution network at the KB-1 substation on the performance of one synchronous motor of the KB-1 pumping station.

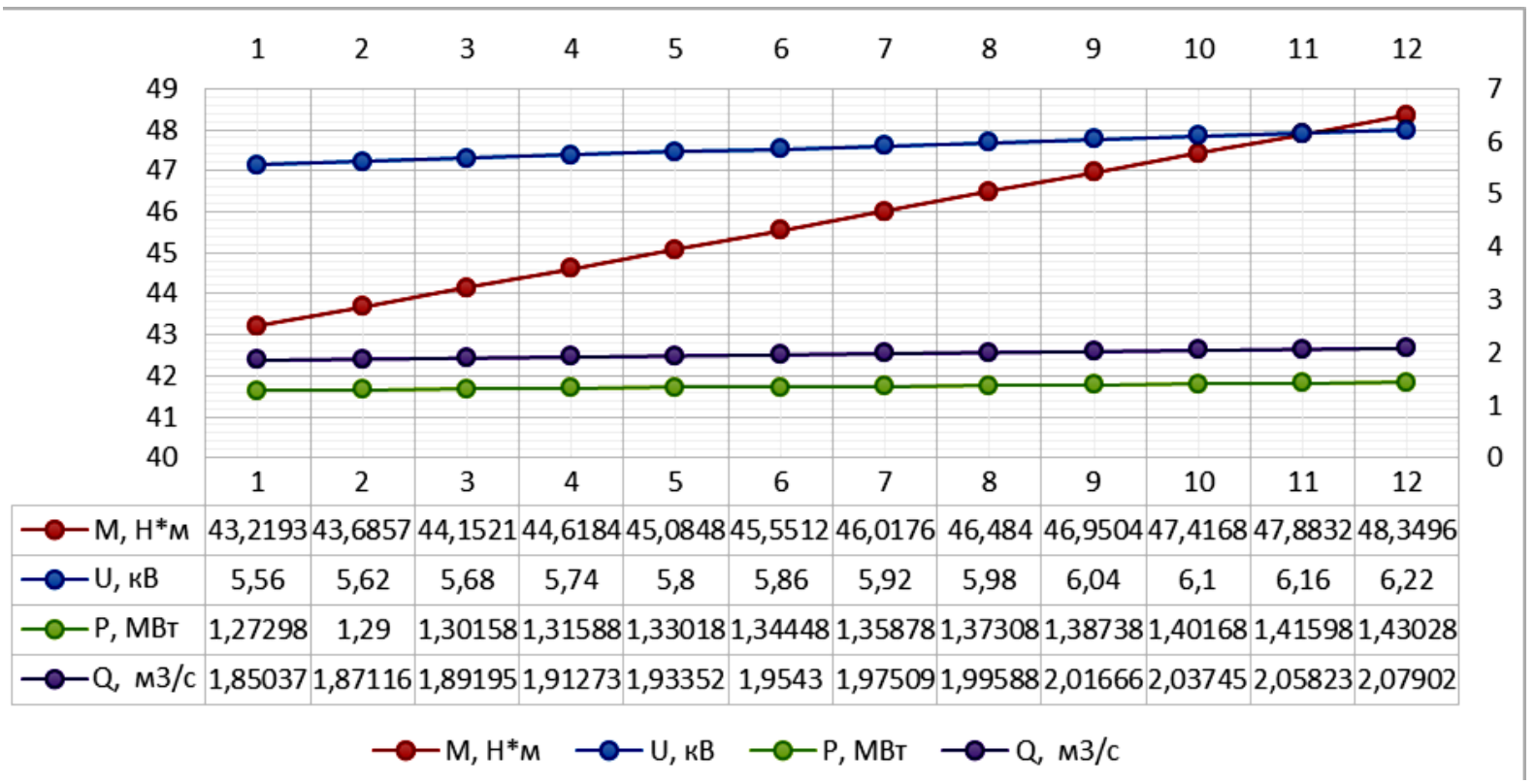

Figure 3. Productivity of the pumping station with a voltage drop from 1 to $10 \%$

According to Figure 3, a decrease in the voltage of the distribution network and short pulses of the power system causes disturbances in the operation of synchronous motors and leads to an increase in temperature in the stator and rotor windings, which leads to increased aging of electrical materials. To prevent the above consequences, it is required to analyze and check electrical devices and protective devices of relay protection and automation systems in the pumping station itself and the distribution network as a whole.

Evaluation of efficiency and control over the implementation of control decisions aimed at improving the design, manufacturing technology and other possible factors causing a decrease in the severity of probable consequences and failures, can also be aimed at achieving the required safety characteristics [10].

During the operation of high-voltage synchronous motors in the pumping station KB-1, an algorithm for calculating the equivalent circuit was developed according to Figure 2 according to the requirements of the direct criterion of static stability. For this purpose, the angular characteristic of a synchronous motor was built (see Fig. 4).

The traditional way of accounting for uncertainty factors on the basis of probabilistic and statistical modeling often turns out to be inadequate to the tasks being solved and can lead to incorrect results, since the functioning of complex organizational and technical systems in practice is characterized by an uncertainty of a "nonstochastic" type [11]. 


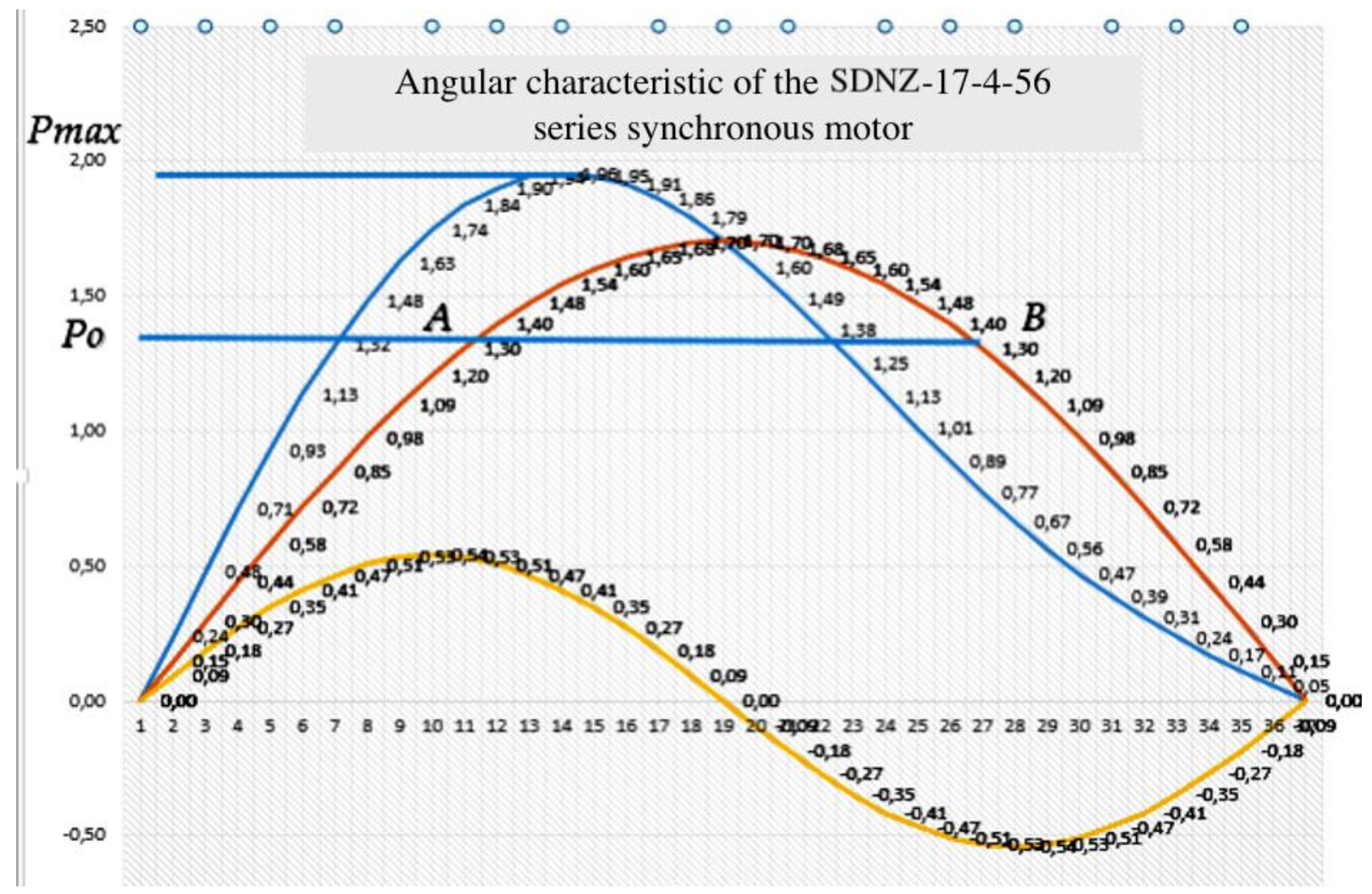

Figure 4. Angular characteristic of the SDNZ-17-4-56 series synchronous motor

According to Figure 4, the engine operation mode is stable with respect to small disturbances if the derivative of the electric power $\mathrm{P}$ with respect to the angle $\square$ is greater than zero. According to the requirement of the direct criterion of static stability, the safety factor for the power of one synchronous motor in normal mode is $20 \%$, and in emergency mode not less than $8 \%$ [12]. Calculations have shown that with short-term small and large values of voltage drop or in the event of interruptions in the power supply, energy-intensive motors operate in a steady state [13] [14].

\section{Conclusion}

As a result of the study, an analysis was made of the causes and factors affecting the failures of electrical equipment elements, a graph of changes in the productivity of the pumping station when the voltage changes, and an algorithm for calculating the productivity of the pumping station was developed and direct criteria of static stability were applied to determine the conditions for stable operation of synchronous motors. The results in the form of graphs and characteristics were obtained using the computer program Microsoft Excel.

\section{References}

1. V.A. Venikov, Transient electromechanical processes in electrical systems. Moscow: Higher school, 536, 1985.

2. A. Germanovich, Algorithm and analysis of the construction of the geometry of the movement of vehicles, International Journal of Advanced Trends in Computer Science and Engineering, 9(2), 14731478, 2020. doi:10.30534/ijatcse/2020/86922020

3. G. Amosov, Selection of the rotation angle law of the special vehicles' wheels, International Journal of Emerging Trends in Engineering Research, 8(4), 1086-1089, 2020. doi:10.30534/ijeter/2020/22842020

4. M. Y. Kuprikov, L. N.Rabinskiy, andN. M. Kuprikov, Infrastructure climate requirements imposed to design of transport airplane for arctic exploration. INCAS Bulletin, 11, 175-181, 2019. doi:10.13111/2066-8201.2019.11.S.17

5. J. Vohidov, Impact of power quality on the operation of irrigation systems. Cheboksary, Publishing house of the Chuvash University, $171-175,2017$.

6. V. Azanov, M. V. Azanov, A. G. Amosov, S. V. Khlopkovand A. A. Khodyakov, Study of impact of tribotechnical composition on rubber technical products to assess its applicability in wheeled transport engine, Paper presented at the IOP Conference Series: Materials Science and Engineering, 632(1), 2019. doi:10.1088/1757-899X/632/1/012049 
7. A. V. Azanov, A. G. Amosov, S. V. Khlopkov andA. A. Khodyakov, Effects of tribotechnical composition, engine oil, and iso-octane on samples of elastomers of automobile technology in aviation industry, International Journal of Advanced Trends in Computer Science and Engineering, 8(5), 22362239, 2019. doi:10.30534/ijatcse/2019/58852019

8. V. A. Golikov, M. E. Vyacheslavovna, A. G. Amosov andO. Roždestvenskis, Unifying the exterior of complex technical systems in modern design, Journal of Advanced Research in Dynamical and Control Systems, 12(7 Special Issue), 988-991, 2020. doi:10.5373/JARDCS/V12SP7/20202193

9. S.I. Gamazin, V.A.Stavtsev, S.A. Tsyruk, Transient processes in industrial power supply systems due to electric motor load. Moscow: MEI Publishing house, 424, 1997.

10. V. A. Golikov, A. G. Amosov andS. Čapulis, Parametric decomposition of failure criticality of complex technical systems, Journal of Advanced Research in Dynamical and Control Systems, 12 (7 Special Issue), 984-987, 2020. doi:10.5373/JARDCS/V12SP7/20202192

11. E. V. Mikhailova, A. G. Amosov and S. Čapulis, Non stochastic type of models in forming the appearance of heavy engineering systems, Journal of Advanced Research in Dynamical and Control Systems, 12(7 Special Issue), 978-983, 2020. doi:10.5373/JARDCS/V12SP7/20202191

12. P.A. Dolin, Fundamentals of safety in electrical installations, 2nd ed. Moscow: Energoatomizdat, 448, 1984.

13. V.K. Shabad, Electromechanical transients in electrical power systems, Moscow: Academy, 192, 2013.

14. A.D. Vohidov, Study of the causes of failure of electrical equipment of high-power pumping stations, Bulletin of the Tula State University. Technical science, 13, 2018. 